\title{
Ocular Complications of Bone Marrow Transplantation
}

\author{
S. J. LIVESEY, J. A. HOLMES*, J. A. WHITTAKER* \\ Cardiff.
}

\begin{abstract}
Summary
Thirty-four patients who had undergone bone marrow transplantation (BMT) were examined; $83.3 \%$ of those who received single shot and none of those who received fractionated total body irradiation (TBI) developed cataracts. The use of steroids to treat chronic Graft Versus Host Disease (GVHD) produced more severe cataracts in those who had allogeneic transplants after single shot TBI, but follow-up has not been long enough to assess their effect following fractionated TBI. Keratoconjunctivitis sicca (KCS) was seen in $81.8 \%$ of patients with chronic GVHD and in $33.3 \%$ of patients after autologous BMT.
\end{abstract}

Bone marrow transplantation is now well recognised as a treatment for aplastic anaemia and severe haematological malignancy. Patients either receive autologous marrow taken whilst in remission and stored for reinfusion at a later date, or donor marrow from a tissue matched relative or a matched but unrelated donor. Prior to infusion of the marrow, the patients receive high-dose chemotherapy alone or in combination with TBI to eradicate all host malignant tissue and minimise rejection of the donor marrow. The major noninfective complication of allogeneic BMT is Graft Versus Host Disease which affects principally the skin, eyes and GI tract and may be fatal. The aim of this study was to investigate the ocular complications of BMT and chronic GVHD.

\section{Patients and Methods}

Between March 1983 and February 1988, 68 BMTs were performed on 63 patients in Cardiff. Included are 23 patients who received autologous marrow, three having double autotransplants, 40 undergoing allogeneic
BMT, two having double transplantation. At the time of the study, 34 patients were available for evaluation. Of these, twelve received autologous marrow: five males aged 19-56 years (mean 40 years) and seven females aged 24-61 years (mean 45.1 years). The three double autotransplants were performed on males aged 19 and 23 years as planned procedures and one female aged 24 years for relapsed acute myeloid leukaemia (AML). A further 22 patients received allogeneic marrow: fourteen males aged $12-45$ years (mean 28.3 years) and eight females aged $19-49$ years (mean 36.75 years). One male aged 29 years underwent two allogeneic BMTs for relapsed chronic myeloid leukaemia (CML).

Informed consent was obtained from all patients who underwent an ophthalmic examination including best corrected visual acuity for both near and distance, assessment of the pre-corneal tear film and extent of conjunctival and corneal staining with Rose Bengal. The lens and fundus were examined after pupillary dilation with one per cent Tropicamide. Schirmers test was performed and 
the extent of cataract formation graded according to Crews' classification. ${ }^{1}$

\section{Results}

\section{(1) Autologous BMT}

There were twelve patients in this group (Table I). Of nine patients receiving TBI, five were given $950 \mathrm{cGy}$ as a single shot and four were given fractioned radiation of five fractions to a total dose of $1125 \mathrm{cGy}$. Of the three patients who underwent two BMTs, two received single shot and one fractionated TBI, all at the time of the second transplant.

Cataracts developed in four patients who received single shot TBI. Of these, three patients had Grade I posterior subcapsular lens opacities (PSCLO), the time of examination varying between 23 and 42 months post transplantation, and one patient had Grade II PSCLO 29 months post BMT, having taken steroids for three months for oral bleeding. Another patient after single shot TBI had no cataract after 22 months follow-up, and one patient (aged 61 years) who had no TBI and no steroids had Grade I PSCLO. None of these patients complained of any visual difficulties. Within a follow-up period of 9 to 18 months, no cataracts were detected in the four patients who received fractionated TBI.

Only one patient (Patient 2) complained of symptoms suggestive of dry eye which were relieved by artificial tear drops prescribed by her General Practitioner, but this was not con- firmed either on examination or by Schirmers test. In six eyes of four patients, there was patchy inferior conjuctival staining with a normal cornea. Schirmers test confirmed a tear flow of less than $6 \mathrm{~mm}$ in five minutes in four eyes of three patients. The patient who had reduced tear flow in both eyes (aged 53 years) received no TBI. Of the other three patients, two received single shot and one fractionated (normal Schirmers test) TBI. In three eyes of two patients, there was reduced tear flow on Schirmers test, but no clinical evidence of KCS.

A mild follicular reaction of the superior tarsal conjunctiva was seen in four patients, another suffered a peripheral retinal venular occlusion and Patient 5 developed Herpes Zoster Ophthalmicus with corneal involvement.

\section{(2) Allogeneic BMT}

This group included 22 patients (Table II): 18 receiving TBI, 12 given as a single shot, five fractionated and the patient who underwent double transplantation had single shot before his first transplant and fractionated before the second. The total dose of radiation was the same as for autologous BMT. Chronic GVHD developed in 11 of the 22 patients $(50 \%)$, all but one of these having been preceded by acute GVHD. Within this group, seven of the patients received single shot, two fractionated and two no TBI. Another nine patients (four

Table I Autologous BMT

\begin{tabular}{|c|c|c|c|c|c|c|c|c|}
\hline Patient & Age & $\operatorname{Sex}$ & Diagnosis & $T B I$ & Steroids & Cataract & Dry Eye & Review (months) \\
\hline 1 & 19 & $\mathbf{M}$ & AML & $\mathrm{S}$ & No & I & + & $42 / 24$ \\
\hline 2 & 36 & $\mathrm{~F}$ & AML & $\mathrm{S}$ & No & I & - & 23 \\
\hline 3 & 24 & $\mathrm{~F}$ & AML & $\mathrm{S}$ & No & I & + & $42 / 25$ \\
\hline 4 & 50 & $\mathrm{~F}$ & CML & $\mathrm{S}$ & Yes & II & - & 29 \\
\hline 5 & 44 & $\mathrm{~F}$ & AML & $\mathrm{S}$ & No & 0 & - & 22 \\
\hline 6 & 53 & $\mathbf{M}$ & AML & $\mathrm{F}$ & No & 0 & + & 18 \\
\hline 7 & 50 & $\mathbf{M}$ & AML & $\mathrm{F}$ & No & 0 & - & 17 \\
\hline 8 & 48 & $\mathrm{~F}$ & AML & $\mathrm{F}$ & No & 0 & - & 10 \\
\hline 9 & 23 & $\mathbf{M}$ & AML & $\mathrm{F}$ & No & 0 & - & $19 / 9$ \\
\hline 10 & 53 & $\mathrm{~F}$ & AML & No & No & 0 & + & 8 \\
\hline 11 & 61 & $\mathrm{~F}$ & AML & No & No & I & - & 8 \\
\hline 12 & 56 & M & AML & No & No & 0 & - & 5 \\
\hline
\end{tabular}

S-Single shot TBI

F-Fractionated TBI

AML-Acute Myeloid Leukaemia

CML_Chronic Myeloid Leukaemia 
Table II Allogenic BMT

\begin{tabular}{|c|c|c|c|c|c|c|c|c|c|c|}
\hline \multirow[b]{2}{*}{ Patient } & \multirow[b]{2}{*}{ Age } & \multirow[b]{2}{*}{ Sex } & \multirow[b]{2}{*}{ Diagnosis } & \multirow[b]{2}{*}{$T B I$} & \multicolumn{2}{|c|}{$G V H D$} & \multirow{2}{*}{$\begin{array}{c}\text { Steroid } \\
\text { Duration } \\
\text { (days) }\end{array}$} & \multirow{2}{*}{$\begin{array}{l}\text { Dry } \\
\text { Eye }\end{array}$} & \multirow[b]{2}{*}{ Cataract } & \multirow{2}{*}{$\begin{array}{l}\text { Review } \\
\text { (months) }\end{array}$} \\
\hline & & & & & $A c$ & $C h$ & & & & \\
\hline 13 & 19 & $\mathrm{~F}$ & CML & $S$ & + & + & 91 & + & III & 63 \\
\hline 14 & 18 & $\mathbf{M}$ & ALL & $\mathrm{S}$ & + & - & 35 & - & IV & 54 \\
\hline 15 & 43 & $\mathrm{~F}$ & $\mathrm{AML}$ & $\mathrm{S}$ & + & + & 193 & - & IV & 48 \\
\hline 16 & 24 & $\mathbf{M}$ & AML & $S$ & + & - & - & - & IV & 47 \\
\hline 17 & 21 & $\mathbf{M}$ & AML & $\mathrm{S}$ & + & + & 456 & - & IV & 44 \\
\hline 18 & 22 & $\mathbf{M}$ & AML & $\mathrm{S}$ & - & - & - & - & IV & 43 \\
\hline 19 & 37 & $\mathrm{~F}$ & CML & $\mathrm{S}$ & + & + & 14 & + & IV & 36 \\
\hline 20 & 26 & $\mathbf{M}$ & AML & $\mathrm{S}$ & + & + & 956 & + & IV & 31 \\
\hline 21 & 49 & $\mathrm{~F}$ & ALL & $\mathrm{S}$ & + & + & $?$ & + & IV & 26 \\
\hline 22 & 28 & $\mathbf{M}$ & ALL & $\mathrm{S}$ & + & - & 111 & - & 0 & 23 \\
\hline 23 & 39 & $\mathrm{~F}$ & AML & $S$ & + & - & 7 & - & 0 & 20 \\
\hline 24 & 39 & $\mathbf{M}$ & CML & $\mathrm{S}$ & + & + & 600 & + & IV & 27 \\
\hline 25 & 29 & $\mathbf{M}$ & CML & $S \& F$ & + & - & 13 & - & IV & $51 / 15$ \\
\hline 26 & 44 & $\mathrm{~F}$ & Myeloma & $\mathrm{F}$ & - & + & 113 & + & 0 & 12 \\
\hline 27 & 25 & $\mathrm{~F}$ & CML & $\mathrm{F}$ & + & - & 50 & - & 0 & 12 \\
\hline 28 & 45 & $\mathbf{M}$ & CLL & $\mathrm{F}$ & + & + & 39 & + & 0 & 12 \\
\hline 29 & 38 & $\mathrm{~F}$ & $A M L$ & $\mathrm{~F}$ & + & - & 10 & - & 0 & 4 \\
\hline 30 & 33 & $\mathbf{M}$ & CML & $\mathrm{F}$ & + & - & $?$ & + & 0 & 5 \\
\hline 31 & 30 & $\mathbf{M}$ & $\mathrm{AA}$ & - & + & + & $?$ & + & 0 & 24 \\
\hline 32 & 34 & $\mathbf{M}$ & NHL & - & + & + & 173 & + & 0 & 10 \\
\hline 33 & 35 & $\mathbf{M}$ & $\mathrm{CML}$ & - & - & - & - & - & 0 & 11 \\
\hline 34 & 12 & $\mathbf{M}$ & $\mathrm{AA}$ & - & + & - & 7 & - & 0 & 33 \\
\hline
\end{tabular}

ALL-Acute Lymphoblastic Leukaemia

CLL_Chronic Lymphoblastic Leukaemia

AA-Aplastic Anaemia

NHL-Non-Hodgkin's Lymphoma

single shot, three fractionated, one none and one both) suffered acute GVHD, but with no signs of chronic GCHD up to the time of the study.

Of the thirteen patients who received single shot TBI (including the patient who had both), one had Grade III and ten Grade IV PSCLO after follow-up of 26-63 months. The other two had no evidence of cataracts (follow-up 20 and 23 months). None of those receiving fractionated $\mathrm{TBI}$ had any evidence of cataract formation (follow-up 4-12 months). Seven of the patients with Grade III or IV PSCLO had suffered chronic GVHD needing treatment with systemic steroids and two of the others received steroids to treat acute GVHD. Only two patients with cataracts (follow-up 43 and 47 months) did not take steroids. All patients given fractionated TBI received steroids, three for acute and two for chronic GVHD. The four patients without TBI have not developed cataracts, although two were given steroids for chronic GVHD (follow-up 10 and 24 months). A third patient took steroids for acute GVHD, but only for seven days.

Of the eleven patients with chronic GVHD, eight have symptomatic KCS (five single shot, two fractionated and one no TBI) and another (Patient 31), who received no TBI, has corneal and conjunctival staining with reduced tear flow of Schirmers test, but is asymptomatic. One other patient without chronic GVHD but who received fractionated TBI, has clinical KCS (Rose Bengal staining and reduced Schirmers test). Only two patients with chronic GVHD have no ocular problems (both single shot TBI). Two patients with chronic GVHD and KCS have developed more serious sequelae of dry eyes. Patient 20, aged 26 years, developed persistent corneal epithelial loss with corneal stromal thinning which resolved leaving widespread vascularised corneal scars. Patient 32, aged 34 years, developed a sterile corneal ulcer.

A mild superior tarsal follicular reaction 
was seen in three patients, a further three had some superior tarsal scarring (all with a history of acute GVHD) and one patient suffers recurrent episodes of episcleritis.

\section{Discussion}

Cataract formation after exposure to ionising radiation has been recognised since $1897 .^{2}$ Merriam and Focht ${ }^{3}$ estimated the minimal dose to produce a cataract in man was $2 \mathrm{~Gy}$ in a single dose, $4 \mathrm{~Gy}$ if given over three weeks to three months, and 5.5 Gy if given over longer than three months. However, they also point out that over the same time interval doses as high as 10-11 Gy have been given without cataract formation.

Total body irradiation and chemotherapy is used as a conditioning regime prior to BMT both to kill all host malignant cells and to suppress the host immune response and thus minimise rejection of the donor marrow. Our findings of an $83.3 \%$ incidence of cataracts after single shot TBI agrees with previously reported figures. ${ }^{4.5}$ Deeg et al., ${ }^{6}$ report a relative risk of developing cataract after single shot TBI 4.77 times greater than after fractionated TBI or no TBI at all. They were surprised to find the incidence in patients who received fractionated TBI to be no greater than the $19 \%$ in patients who had no TBI. We found no patients with cataract after fractionated TBI, although the longest follow-up in this group was 18 months. Of the six patients who had no TBI, one developed Grade I PSCLO at the age of 61 years, which may therefore have been unrelated to the transplant. Significantly, it has been found that $50 \%$ of patients with cataract after single shot TBI need surgery with a median of six years post BMT compared to only $20 \%$ who had fractionated TBI and none who had no TBI. ${ }^{4}$ These figures suggest that as well as reducing the incidence of cataracts, fractionated TBI may also reduce the clinical severity of the cataracts that do develop.

Deeg et al., ${ }^{6}$ also analysed factors other than radiation which may have contributed to the development of cataract. Significant factors were found to be acute and chronic GVHD, steroid use after Day 100 and initial diagnosis. There was a higher incidence in patients with acute lymphoblastic leukaemia
(ALL) which did not appear to have been influenced by pre-transplant cranial irradiation. It may, however, have been related to pre-transplant treatment with systemic steroids. A $52 \%$ incidence of PSCLO has been reported in survivors of ALL who had not undergone BMT. ${ }^{7}$

The effect of long term use of systemic steroids on the formation of PSCLO was first reported by Black in 1960 in patients with rheumatoid arthritis. ${ }^{8}$ Cataracts were not seen if the duration of treatment was less than one year, but $11 \%$ of those taking a moderate dose and $78 \%$ a high dose developed cataracts in 1-4 years, the incidence increasing the longer the duration of treatment. None of the patients were taking the huge doses needed in the treatment of GVHD often starting with 3 gm Methyl-Prednisolone daily, albeit usually with quick dosage reduction. Younger patients tend to develop cataracts at lower doses and within a shorter time period. ${ }^{9}$

Within a follow-up period of $23-42$ months, four out of five patients who received autologous transplants with single shot TBI developed Grade I or II PSCLO. The five patients with cataracts after single shot TBI and allogeneic BMT who had been seen at a similar time post transplant (26-44 months) all had Grade IV PSCLO. All but one of these patients had received steroids for chronic GVHD. Longer follow-up is needed to draw any conclusions about the effects of systemic steroids after fractionated TBI, but Deeg reports that steroids are a significant factor, as the incidence of cataracts after fractionated TBI in those who had no steroids was only $9 \% .^{6}$

The Seattle Transplantation Group report that $55-90 \%$ (depending on initial diagnosis) of patients undergoing BMT survive with no recurrence of their disease. ${ }^{10}$ Acute GVHD develops within the first 100 days post transplantation producing an exanthematous dermatitis, hepatitis and enteritis. Ten per cent also have ocular problems including proptosis, cranial nerve palsies, intra-retinal haemorrhages and herpes simplex/zoster infections ${ }^{11}$. However, the commonest finding in a group of patients in Seattle was of a culture negative haemorrhagic conjunctivitis, which proceeded to an exudative phase with 
ulceration of the superior tarsal conjunctiva and pseudomembrane formation on the inferior tarsal conjunctiva. This resolved leaving characteristic scarring which was seen in three Cardiff patients, all of whom had a history of acute GVHD.

In $25-45 \%$ of long term survivors, chronic GVHD develops. ${ }^{12.13,14}$ This occurs by definition more than 100 days post transplantation and may be a continuation of acute GVHD, follow acute GVHD or arise de novo. Most investigators believe that it represents an immunological process mediated by immunocompetent donor lymphocytes reacting to genetically determined histocompatibility differences in the host. ${ }^{15}$ Several reports have shown an imbalance in both humoral and cell mediated immune regulation including hypergammaglobulinaemia, ${ }^{13,16}$ deposits of immunoglobulin and complement at the dermoepidermal junction of the skin, ${ }^{17}$ and the presence of autoantibodies. ${ }^{13}$

Clinically, chronic GVHD has similarities with autoimmune disorders such as systemic sclerosis, SLE, lichen planus and Sjögrens syndrome. Organs involved include the mouth, nose, eyes, liver, GI tract, lung, musculoskeletal, haematologic and lymphoid systems. ${ }^{18}$ The most frequent ocular abnormality is a Sjögren-like syndrome first described by Lawley et al., ${ }^{19}$ and Gratwohl et al. ${ }^{20}$ who also demonstrated lymphocyte and plasmacyte infiltration into the minor salivary glands identical to that of Sjögrens syndrome. Other reported findings in chronic GVHD include cicatricial lagophthalmos, sterile conjunctivitis and uveitis. ${ }^{21}$

In this study, $50 \%$ of patients who underwent allogeneic BMT developed chronic GVHD, $81.8 \%$ of these with ocular involvement of type and frequency comparable with previous reports. ${ }^{4.14,21,22}$ After autologous BMT, four patients (two single shot, one fractionated and one no TBI) had clinical evidence of reduced tear production in one or both eyes, but none of these patients was symptomatic. The patient who had no TBI with bilateral KCS at the age of 53 years has serology consistent with Sjögrens syndrome. Keratoconjunctivitis sicca may follow direct irradiation to the lacrimal apparatus. Parsons et al. ${ }^{23}$ report severe dry eye problems in 19 patients who received direct irradiation of the orbit for orbital tumours, but say that most patients will tolerate doses in the range 3,000$4,000 \mathrm{cGy}$ to the entire orbit without developing severe symptoms of a dry eye. It seems likely that orbital irradiation even at the dosage regimen used for marrow transplantation is a contributory factor to the development of $\mathrm{KCS}$ which can no longer be uniquely associated with allogeneic BMT and chronic GVHD.

We are grateful to Dr. Pat Salaman, Consultant Radiotherapist, for her helpful comments.

\section{References}

${ }^{1}$ Crews SJ: Posterior subcapsular lens opacities in patients on long-term cortiocosteroid therapy. $\mathrm{Br}$ Med J 1963; 1: 1644-7.

${ }^{2}$ Chalupecky H: Ueber die Wirkung der Ront genstrahlen auf das Auge und die Haut. Zantralbl $f$ prak Augenh 1897; 21: 234, 267, 886.

${ }^{3}$ Merriam GR and Focht EF: A clinical study of radiation cataracts and the relationship to dose. $A m \mathrm{~J}$ Roentgen 1957; 77: 759-85.

${ }^{4}$ Deeg HJ, Storb R, Thomas ED: Bone marrow transplantation: A review of delayed complications. $\mathrm{Br}$ J Haematol 1984; 57: 185-208.

${ }_{5}^{5}$ Tichelli A, Gratwohl A, Speck B, Osterwalder B, Nissen C, Lori A, Wursch A, Walther E, Roth J, Hunig R: Nebenwirkungen der Ganzkorperbestrahlung in Rahmen der Knochenmark transplantation: Prophylaxe and Therapie. Schweiz Med Wochenschr 1986; 116 (45): 1560-6.

${ }^{6}$ Deeg HJ, Flournoy N, Sullivan KM, Sheenan K, Buckner CD, Sanders JE, Storb R, Witherspoon RP, Thomas ED: Cataracts after total body irradiation and marrow transplantation: A sparing effect of dose fractionation. Int J Radiat Oncol Biol Phys 1984; 10(7): 957-64.

${ }^{7}$ Hoover DL, Smith LEH, Turner SJ, Gelber RD, Sallan SE: Ophthalmic evaluation of survivors of acute lymphoblastic leukaemia. Ophthalmology 1988; 95(2): 151-5.

${ }^{8}$ Black RL, Oglesby RB, von Sallmann L, Bunim JJ: Posterior subcapsular cataracts induced by corticosteroids in patients with rheumatoid arthritis. J Am Med Ass 1960; 174: 166-71.

${ }^{9}$ Loredo A, Rodriguez RS, Murillo L: Cataracts after short-term cortico-steroid treatment. N Engl J Med 1972; 286(1): 160.

${ }^{10}$ Thomas ED, Buckner CD, Clift RA, Fefer A, Johnson FL, Neiman PE, Sale GE, Sanders JE, Singer JW, Shulman H, Storb R, Weiden PL: Marrow transplantation for acute nonlymphoblastic leukaemia in first remission. N Engl J Med 1979; 301(1): 597-9.

11 Jack MK, Jack GM, Sale GE, Shulman HM, Sullivan KM: Ocular manifestations of Graft-v-Host Disease. Arch Ophthalmol 1983; 101: 1080-4. 
12 Sullivan KM, Shulman HM, Storb R, Weiden PL, Witherspoon RP, McDonald GB, Schubert MM, Atkinson K, Thomas ED: Chronic Graft-versusHost disease in 52 patients: Adverse natural course and successful treatment with combination immunosuppression. Blood 1981; 57: 267-76.

13 Graze PR and Gale RP: Chronic Graft Versus Host Disease: A syndrome of disordered immunity. Am J Med 1979; 66: 611-20.

${ }^{14}$ Shulman HM, Sale GE, Lerner KG, Barker EA, Weiden PL, Sullivan K, Galluci B, Thomas ED, Storb R: Chronic cutaneous Graft-versus-Host Disease in man. Am J Pathol 1978; 91: 545-70.

15 Grebe SC and Streilein JW. Graft-versus-Host reactions: A review. Adv Immunol 1976; 22: 119-221.

${ }^{16}$ Noel DR, Witherspoon RP, Storb R, Atkinson K, Doney K, Mickelson EM, Ochs HD, Warren RP, Weiden PL, Thomas ED: Does Graft-VersusHost Disease influence the tempo of immunologic recovery after allogeneic human marrow transplantation? An observation on 56 long-term survivors. Blood 1978; 51(2): 1087-105.

17 Tsoi MS, Storb R, Jones E, Weiden PL, Shulman H, Witherspoon R, Atkinson K, Thomas ED: Deposition of IgM and complement at the dermo-epidermal junction in acute and chronic cutaneous Graft-Vs-Host disease in man. J Immunol 1978; 120: $1485-92$.
${ }^{18}$ Shulman HM, Sullivan KM, Weiden PL, McDonald GB, Striker GE, Sale GE, Hackman R, Tsoi MS, Storb R, Thomas ED: Chronic Graft-VersusHost syndrome in man: A long-term clinicopathologic study of 20 Seattle patients. $\mathrm{Am}$ J Med 1980; 69: 204-17.

${ }^{19}$ Lawley TJ, Peck GL, Moutsopoulos HM, Gratwohl AA, Deisseroth AB: Scleroderma, Sjögren-like syndrome, and chronic Graft-Versus-Host Disease. Ann Intern Med 1977; 87: 707-9.

${ }^{20}$ Gratwohl AA, Moutsopoulos HM, Chused TM, Akizuki M, Wolf RO, Sweet JB, Deisseroth AB: Sjögren-Type syndrome after allogeneic bonemarrow transplantation. Ann Intern Med 1977; 87: 703-6.

${ }^{21}$ Franklin RM, Kenyon KR, Tutschka PJ, Saral R, Green WR, Santos GW: Ocular manifestations of Graft-vs-Host Disease. Ophthalmology 1983; 901(1): 4-13.

22 Hirst LW, Jabs DA, Tutschka PJ, Green WR, Santos GW: The eye in bone marrow transplantation. I Clinical Study. Arch Ophthalmol 1983; 101(4): 580-4.

${ }^{23}$ Parsons JT, Fitzgerald CR, Hood CI, Ellingwood KE, Bova FJ, Million RR: The effects of irradiation on the eye and optic nerve. Int J Radiat Oncol Biol Phys 1983; 9(5): 609-22. 